\title{
Spectral Analysis and Growth of Nd:YLF Crystal
}

\author{
Dongyang Zheng, Jialin Xu, Wang Liu, Ximeng Cheng, Weizhao Jin, Chun Li, Fanming Zeng, Hai Lin, \\ Jinghe Liu \\ Changchun University of Science and Technology \\ Changchun, 130022, China \\ e-mail: lichun1210@163.com
}

\begin{abstract}
-
Nd: YLF polycrystalline raw materials were synthezed by a dry method and Nd:YLF laser crystal was grown by IF indu ction $\mathrm{Cz}$ method.Its process parameters were these:a pulling rate of $1 \mathrm{~mm} / \mathrm{h}$, the crystal rotation speed of $15 \mathrm{r} / \mathrm{min}$ and $10^{-}$

${ }^{2} \mathrm{~Pa}$ degree of vacuum. The absorption and fluorescence spect ra of crystal indicates that the Nd:YLF crystal has strong sbs orptions around $808 \mathrm{~nm}$ at room temperature which belong $t$ o commercial laser diode band and under the $808 \mathrm{~nm}$ diode la ser pumped, the fluorescence emission peaks of Nd:YLF crys tal are located at 1050 and $1300 \mathrm{~nm}\left({ }^{4} \mathrm{~F}_{3 / 2} \rightarrow{ }^{4} \mathrm{I}_{11 / 2}\right)$ have stronge $r$ emission.
\end{abstract}

Keywords-Nd: YLF; Crystal growth; spectral analysis

\section{INTRODUCTION}

In recent years, the development of solid-state laser is characterized by diversity, multi-wavelength technology. The yttrium lithium fluoride crystal which has good optical performance has become one of the hot laser crystal. As a kind of high efficiency laser material that fit a number of important laser applications, YLF crystals have excellent material characteristics and spectral properties, when incorporated into a variety of rare earth ions and activated sensitizer ions, it can be obtained from the UV $0.3 \mu \mathrm{m}$ to mid-infrared $3.9 \mu \mathrm{m}$ more than 20 band infrared laser transition, etc ${ }^{[1-3]}$.

$\mathrm{Nd}$ :YLF crystal is in a tetragonal with space group $\mathrm{I}_{41}$ / a a negative uniaxial crystal with scheelite structure, lattice parameter of $\mathrm{a}=0.526 \mathrm{~nm}, \mathrm{c}=1.094 \mathrm{~nm}$.It can produce 1.047 and $1.053 \mu \mathrm{m}$ laser wavelength, which $1.053 \mu \mathrm{m}$ wavelength matches $\mathrm{Nd}$ doped phosphate glass laser wavelength, it is also an effective working substance for laser oscillator and preamp in laser fusion device $^{[4,5]}$. This crystal has a long life, a relatively wide width, a low thermal lensing effect and natural birefringence to promote the Nd:YLF laser development. Compared to Nd:YAG laser, Nd:YLF solid-state laser is easy to achieve laser technology such as mode-locked, tune Q,frequency, pulse compression. Nd: YLF solid state laser has a high energy storage, high pulse repetition frequency and narrow giant-pulse width. The continuous clamping efficiency of Nd:YLF is 5 times higher YAG solid-state lasers, single-mode output of single-lamppumped reached to $22 \mathrm{~W} \mathrm{Nd:YLF}$ solid-state lasers have been used in laser fusion, regenerative amplifier, synchronously pumped dye lasers, laser micromachining, optical pulse modulation,etc ${ }^{[6-8]}$. It will be also used in laser spectroscopy, nonlinear optics, free-space communications and other fields. We used a dry method to optimize the process parameters of raw materials ratio and synthesize YLF polycrystalline material. And we used medium frequency induction heating pulling method to grow the Nd:YLF laser crystal, research the spectral characteristics of the crystal and analyzed the crystal doped ions in energy level transition.

\section{EXPERIMENT}

Since the growth of Nd:YLF crystal demanding purity raw materials, the chemical reagents $\mathrm{LiF}, \mathrm{YF}_{3}$ and $\mathrm{NdF}_{3}$ were selected by the purity of $99.999 \%$. The polycrystalline materials were prepared by the dry method. Under HF atmosphere, rare earth fluorides were treated by purification processing in high temperature. Put $5 \mathrm{~N}$ rare earth oxide powder after $130^{\circ} \mathrm{C}$ burning in platinum boat of FS-10 fluoride furnace, under flowing HF atmosphere at $600^{\circ} \mathrm{C}$, which will obtain rare earth fluoride $\mathrm{NdF}_{3}$ after reaction.

The polycrystalline materials $\mathrm{NdF}_{3}$ and $\mathrm{LiF}, \mathrm{YF}_{3}$ which were according to the ratio of $\mathrm{LiF}: \mathrm{YF}_{3}=53: 47$ were prepared by the dry method, in which $\mathrm{Nd}$ doped mole fraction was $1 \%$, after mixing placed in platinum crucibles, and used induction heating $\mathrm{Cz}$ method to grow Nd:YLF crystal, the parameters of the growth of crystal were those a pulling rate of $1 \mathrm{~mm} / \mathrm{h}$, the crystal rotation speed of $15 \mathrm{r} / \mathrm{min}, 10^{-2} \mathrm{~Pa}$ degree of vacuum and the growth cycle of $336 \mathrm{~h}$. In order to prevent the oxidation and volatilization of fluorides ,it was grown in the volume ratio of $\operatorname{Ar}(90 \%)$ and $\mathrm{CF}_{4}(10 \%)$ atmosphere and the cooling rate was $30^{\circ} \mathrm{C} / \mathrm{h}$. The size of $\mathrm{Nd}: \mathrm{YLF}$ crystal is about $\phi 26 \mathrm{~mm} \times 150 \mathrm{~mm}$. 


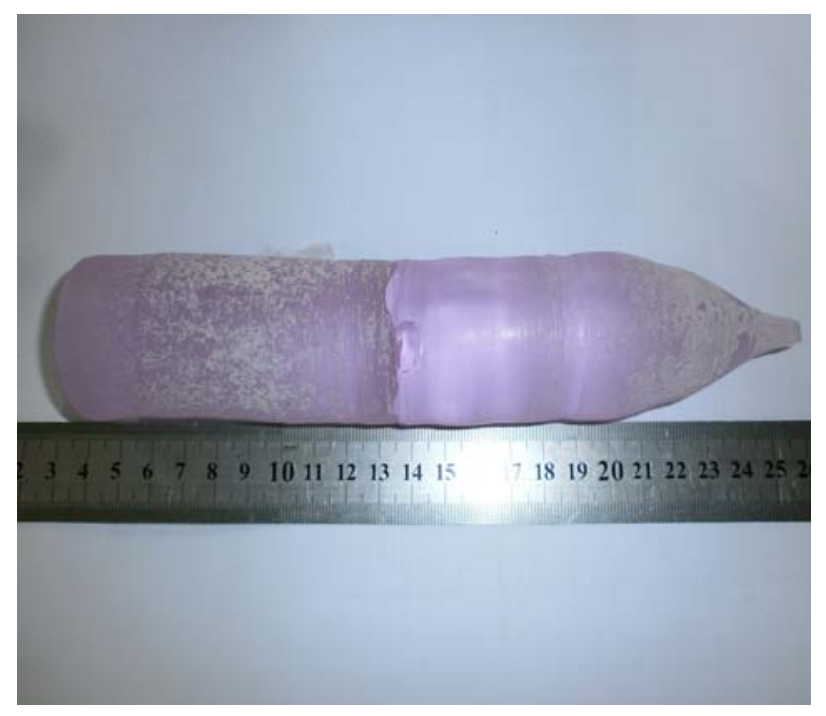

Fig. $1 \mathrm{Nd}$ :YLF crystal

\section{RESULTS AND DISCUSSION}

\section{A. Purification of rare earth fluoride}

Due to the presence of water vapor in the environment, fluoride raw materials readily adsorb moisture and hydrolyze at high temperatures. Also easy to generate oxide impurities, forming oxygen contamination, which is difficult to grow high-quality fluoride crystals. If use the fluoride crystal growth of untreated raw material directly, there will be a lot of white inclusions at the crystal surface. In order to obtain high-quality fluoride laser crystal, we must use the raw materials that not contain moisture and other impurities.It was found that the smaller the particle size of $\mathrm{Nd}_{2} \mathrm{O}_{3}$ is, the more adequate response is. When the particle size of the raw material or the feeding amount is larger, the reaction is incomplete, which will be residual oxide. When the particle size of $\mathrm{REF}_{3}$ is larger, the surface area of it is smaller, which is more difficult to hydrolyze. Therefore, $\mathrm{REF}_{3}$ must be stayed under the atmosphere of $\mathrm{HF}$, heated and melted at $1200^{\circ} \mathrm{C}$, in order to ensure crystal quality. Therefore, we must first let the $\mathrm{YF}_{3}$ rare earth fluoride to be high-temperature purification treatment under the atmosphere of HF, in order to grow high-quality YLF crystal. Rare earth fluoride or the raw material of long-term storage, which is also required to carry out a fluorination treatment before using, so that the residual oxide, fluorine oxide, and anionic impurities will be removed.

\section{B. XRD}

The crystal structure was analyzed by X-ray diffraction (XRD) with a Rigaku $\mathrm{D} / \mathrm{max}-\mathrm{rA}$ revolving target $\mathrm{XRD}$ apparatus, using a $\mathrm{Cu} \mathrm{K} \alpha$ ray $(\lambda=0.154056$ $\mathrm{nm})$ as the radiant. The tube voltage was $50 \mathrm{kV}$ and the tube current was $150 \mathrm{~mA}$, and the apparatus had a graphite monochromator. The result of powder XRD analysis for Nd:LYF crystal is shown in Fig. 2, and the diffraction peaks were assigned. Compared with JCPDS card (17-0874), the x-ray diffraction spectrum shows that the diffraction peaks and relative intensity of the crystal sample is very similar to LYF. Therefore, the crystal belongs to a tetragonal phase with a space group I41/a.

$$
d=\frac{1}{\sqrt{\frac{h^{2}+k^{2}}{a^{2}}+\frac{l^{2}}{c^{2}}}}
$$

According to formula (1) for cell parameters of tetragonal systems, the cell parameters of the $\mathrm{Nd}: \mathrm{LYF}$ crystal are $\mathrm{a}=5.221 \AA \hat{\mathrm{a}} \mathrm{c}=10.978 \AA$ and $\mathrm{Z}=4$. The dopant rare earths substitutionally enter the $\mathrm{Y}^{3+}$ sites, with local symmetry S4.

\section{Absorption Spectroscopy}

The absorption spectrum of the square slice sample was measured with ultraviolet (UV) spectrophotometer (Model UV360, SHIMADZU Company, Japan) in the 350-900nm range at room temperature. Fig. 3 is the absorption spectra of the Nd:YLF crystal within the wavelength range from $350 \mathrm{~nm}$ to $900 \mathrm{~nm}$. From Fig. 3 it sees that the crystal has eight main absorption bands which is corresponding to the transitions of $\mathrm{Nd}$ ions $4 \mathrm{f}$ shell electrons from the ground state ${ }^{4} I_{9 / 2}$ to every excited state state $^{2} \mathrm{P}_{1 / 2},\left({ }^{2} \mathrm{G}_{9 / 2},{ }^{2} \mathrm{D}_{3 / 2}\right.$, $\left.{ }^{2} \mathrm{P}_{3 / 2},{ }^{4} \mathrm{G}_{11 / 2}\right), \quad\left({ }^{4} \mathrm{G}_{9 / 2},{ }^{4} \mathrm{G}_{7 / 2}\right),{ }^{4} \mathrm{G}_{5 / 2},{ }^{4} \mathrm{~F}_{9 / 2},\left({ }^{4} \mathrm{~S}_{3 / 2},{ }^{4} \mathrm{~F}_{7 / 2}\right)$, $\left.{ }^{4} \mathrm{~F}_{5 / 2},{ }^{2} \mathrm{H}_{9 / 2}\right),{ }^{4} \mathrm{~F}_{3 / 2}$. The transitions of $\mathrm{Nd}$ ions belong to narrow band sharp line $4 \mathrm{f}-4 \mathrm{f}$ transitions. Due to the outer electrons in $5 \mathrm{~s}$ and $5 \mathrm{f}$ have shielding effect on electrons in $4 \mathrm{f}$, the electrons in $4 \mathrm{f}$ is little interrupted by the crystal field, thus making the spectra of dopant ions is close to free ions.

The absorption coefficient of $\mathrm{Tm}^{3+}$ ions can be calculated as follows:

$$
\alpha=\frac{\ln \left(\frac{I_{0}}{I}\right)}{L}=\frac{2.303 O D}{L}
$$

where $O D$ is optical density, $L$ is the thickness of the sample $(\mathrm{cm})$. The relation between absorption cross section and absorption coefficient can be expressed as follows:

$$
\sigma_{a}=\frac{\alpha}{N_{0}}
$$

where $N_{0}$ is the number of absorption center per volume.

The absorption coefficient and absorption cross section at the strongest absorption peak of $808 \mathrm{~nm}$ is $5.62 \times 10^{-21} \mathrm{~cm}^{2}$.

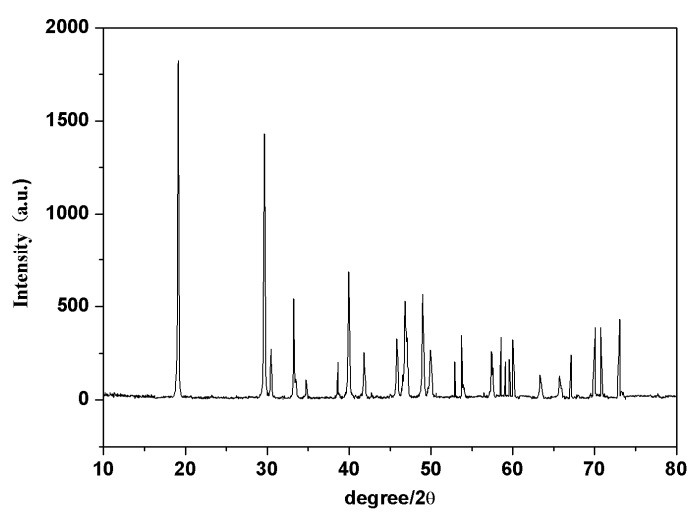

Fig.2 XRD of Nd:YLF 


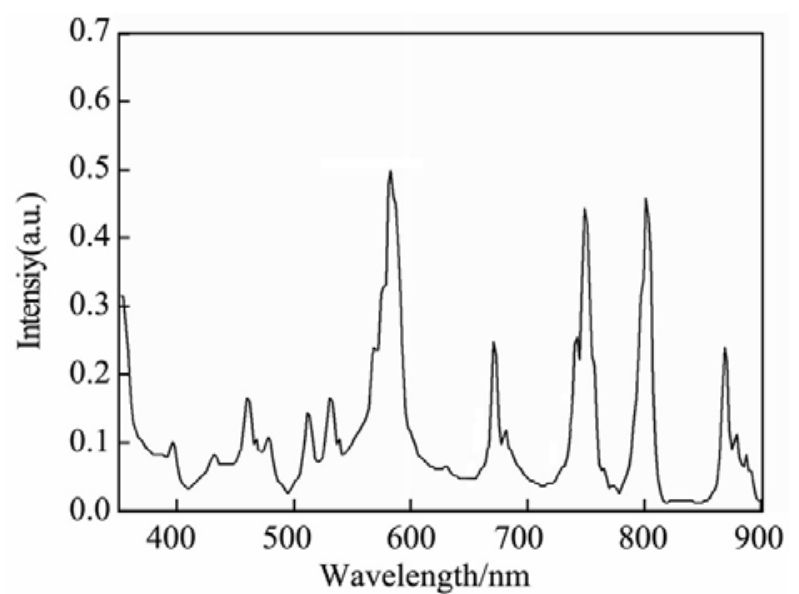

Fig.3 Absorption spectrum of Nd:YLF

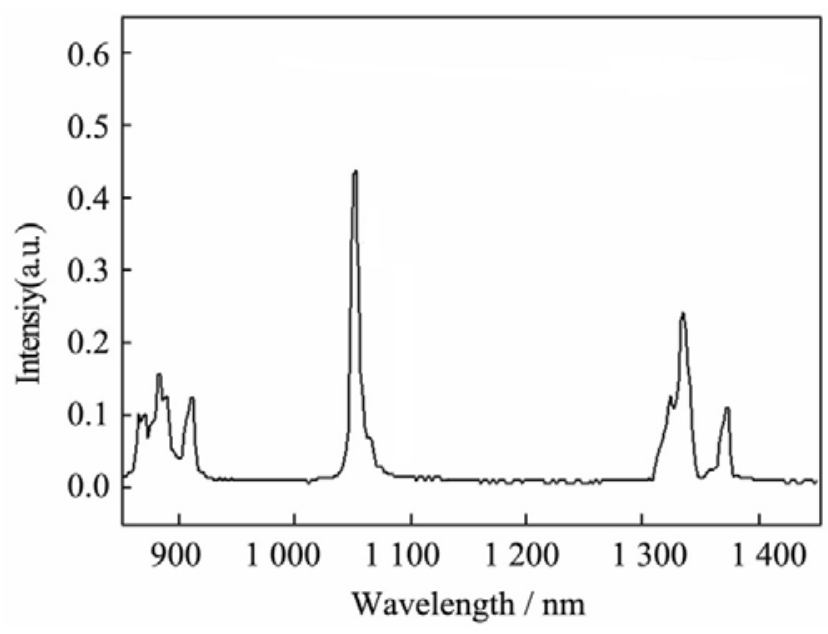

Fig 4 Emission spectrum of Nd:LiYF

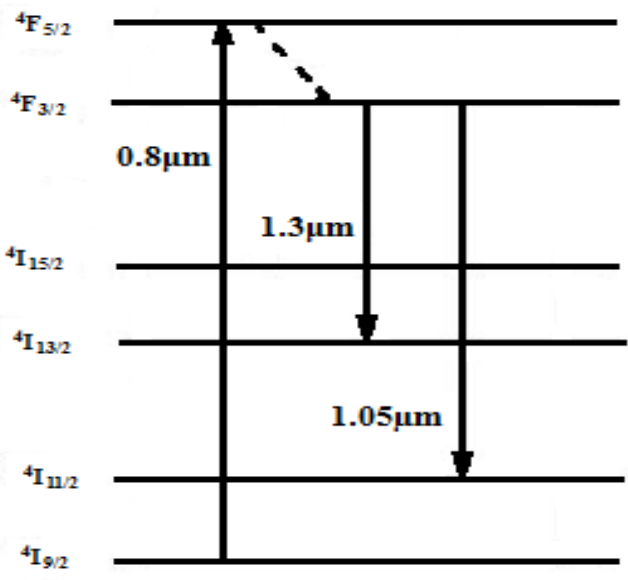

Fig.5 Energy level diagram of the $\mathrm{Nd}^{3+}$ ions

\section{Emission spectrum}

The fluorescence spectrum was measured with a fluorescence spectrometer (Model FluoroLog-3,Horiba Company, Japan) in the $850-1450 \mathrm{~nm}$ range at room temperature, and with the wavelength of $808 \mathrm{~nm}$ excited by an excitation source. Fig. 4 shows the emission spectra of $\mathrm{Nd}$ :YLF crystal was obtained by the $808 \mathrm{~nm}$ diode laser pumped. Fig.4 shows a level transition pattern of the crystal $1.0 \mu \mathrm{m}$ radiation wavelengths includes $1047 \mathrm{~nm}$ and $1053 \mathrm{~nm}$, corresponding to the ${ }^{4} \mathrm{~F}_{3 / 2} \rightarrow{ }^{4} \mathrm{I}_{11 / 2}$ transition, and $1047 \mathrm{~nm}$ wavelength has maximum light intensity.

It is calculated by the following formula ${ }^{[9]}$ for fluorescence emission cross section of the crystal:

$$
\sigma_{e m}(\lambda)=\frac{\lambda^{5} \eta I(\lambda)}{8 \pi n^{2} c \tau \int \lambda I(\lambda) d \lambda}
$$

where $\mathrm{c}$ is the speed of light, $\mathrm{n}$ is the refractive index, $\eta$ is the radiative efficiency that can be estimated from the comparison between the theoretical radiative and the fluorescence lifetime, $I(\lambda)$ represents the experimental emission intensity as a function of the wavelength.

According to Eq.(4), the IR transition is a broad emission band at about $1047 \mathrm{~nm}$ and 1053nm. The maximum emission cross-section of the transition is $1.8 \times 10^{-19} \mathrm{~cm}^{2}$ and $1.2 \times 10^{-19} \mathrm{~cm}^{2}$ near $1047 \mathrm{~nm}$ and $1053 \mathrm{~nm}$.

The stimulated emission cross section corresponding to $1047 \mathrm{~nm}$ wavelength $\left(1.8 \times 10^{-19} \mathrm{~cm}^{2}\right)$ is 1.5 times bigger $1053 \mathrm{~nm}\left(1.2 \times 10^{-19} \mathrm{~cm}^{2}\right)$. Therefore the laser resonator that cut A-axis of crystal was used,the maximal output gain was obtained in $1047 \mathrm{~nm}$ wavelength, the crystal which was cut into the Brewster angle or tilt mirrors method to select $1053 \mathrm{~nm}$ output by adding Brewster piece to the chamber. Crystal which was in the vicinity of $1.3 \mu \mathrm{m}$ has strong emission peaks corresponding to ${ }^{4} \mathrm{~F}_{3 / 2} \rightarrow{ }^{4} \mathrm{I}_{13 / 2}$ transition. Fig.5 Energy level diagram of the $\mathrm{Nd}^{3+}$ ions

\section{CONCLUSIONS}

Using the dry method, designed the LiF:YF3=53:47 ratio, synthesis of $\mathrm{Nd}$ :YLF polycrystalline materials, the use of intermediate frequency induction $\mathrm{Cz}$ method, designed the suitable temperature field, select the pull rate is $1 \mathrm{~mm} / \mathrm{h}$, the crystal speed of $15 \mathrm{r} / \mathrm{min}$, vacuum degree of $10^{-2} \mathrm{~Pa}$, the growth of $\mathrm{Nd}$ :YLF laser crystal $26 \mathrm{~mm} 150 \mathrm{~mm}$. At room temperature, crystals have strong absorption peaks in the near $808 \mathrm{~nm}$, using $808 \mathrm{~nm}$ laser diode pumped $\mathrm{Nd}$ :YLF crystal has a strong emission peak at around $1.05 \mu \mathrm{m}$ and $1.3 \mu \mathrm{m}$, corresponding to ${ }^{4} \mathrm{~F}_{3 / 2},{ }^{4} \mathrm{I}_{11 / 2}$ and $\mathrm{Nd}^{3+}$ ions ${ }^{4} \mathrm{~F}_{3 / 2},{ }^{4} \mathrm{I}_{13 / 2}$ transition.

\section{ACKNOWLEDGEMENTS}

The research work was supported by Advance research(No.40405060401 and No. 62201050304). The authors also wish to thank Dr. Zhi Zhao and Dr. Liaohai Ge for carrying out the tensile tests.

\section{REFERENCES}

[1] Okada F., Togawa S., Ohta K., Koda S. Solid-state ultraviolet tunable laser:A Ce ${ }^{3+}$ doped $\mathrm{LiYF}_{4}$ crystal. Journal of Applied Physics, 75(1),pp.49-53,1994.

[2] Kollia Z., Sarantopoulou E., Cefalas A.C, Naumov A K, Semashko V V, Abdulsabirov R Y, Korableva S L. On the $4 f^{2} 5 d \rightarrow 4 f^{3}$ interconfigurational transitions of $\mathrm{Nd}^{3+}$ ions in $\mathrm{K}_{2} \mathrm{YF}_{5}$ and $\mathrm{LiYF}_{4}$ crystal hosts. Optics Communications, 149(4-6),pp.386-392,1998.

[3] Brede R, Danger T, Heumann E, Huber G. \& Chai B. Roomtemperature green laser emission of Er:LiYF 4 . Applied Physics Letters, 63(6),pp.729-730,1993. 
[4] Davydova M. P., Zdanovich S. B., Kazakov B. N., Korableva S. L. \& Stolov A. L. Stark structure of the spectrum of the $\mathrm{Dy}^{3+}$ ion in a $\mathrm{LiYF}_{4}$ crystal. Spectroscopy Letters, 42(3),pp.327-328,1977.

[5] Namu jilatu, Ruan Yong-feng, Su Xiao-ping, YANG Hai, Yang Peng, \& LI Nan. Growth of $\mathrm{Re}: \mathrm{LiM}(\mathrm{Re}=\mathrm{Tm}, \mathrm{Ce} ; \mathrm{M}=\mathrm{Lu}, \mathrm{Y}) \mathrm{F}_{4}$ Crystal under $\mathrm{CF}_{4}$ Atmosphere. Journal of Synthetic Crystals, 38(3),pp.584-586, 2009.

[6] Leebeeck De. H, GÖrller W. C. Spectroscopic and magnetic properties of $\mathrm{Nd}^{3+}$ in $\mathrm{LiYF}_{4}$. Journal of alloys and compounds, 225(1),pp.75-79,1995.
[7] Sun Y, Zhang H., LIN Q. Huang L, Wang Y \& Gong M. High pulse repetition frequency all-solid-state $1053 \mathrm{~nm} \mathrm{Nd}$ :YLF laser.Laser Physics Letters, 10(7),pp.722-725,2010.

[8] Magni. V, Cerullo. G, Silvestri. De. S., Svelto. O, Qian. L. J. \& Danailov. M. Intracavity frequency doubling of a cw high-power TEM00 Nd:YLF laser. optics letters, 24(18),pp.2111-2113,1993.

[9] Li Chun, Zhang Ying, Zhang Xue-jian, Zeng Fan-ming, Mauro T, Liu Jing-he. Spectral properties of Tm,Ho:LiYF 4 laser crystal Journal of Rare Earths, 29(6),pp.592-595,2011. 